\title{
İki şeftali çeşidinde mavi leğen tuzaklarla yakalanan Tropinota hirta (Poda, 1761) (Coleoptera: Cetoniidae) ergin sayısının karşılaştırılması
}

\section{Comparison of adult numbers of Tropinota hirta (Poda, 1761) (Coleoptera: Cetoniidae) captured with blue basin traps in two peach cultivars}

\author{
Ali ÖZPINAR ${ }^{1 *}$ i , ibrahim ERBAY ${ }^{1}$ (D) \\ ${ }^{1}$ Çanakkale Onsekiz Mart Üniversitesi, Ziraat Fakültesi, Bitki Koruma Bölümü, Çanakkale
}

To cite this article:

Özpınar, A. \& Erbay, i. (2020). ìki şeftali çeşidinde mavi leğen tuzaklarla yakalanan Tropinota hirta (Poda, 1761) (Coleoptera: Cetoniidae) ergin sayısının karşılaştırılması. Harran Tarım ve Gıda Bilimleri Dergisi, 24(3): 250-258.

DOI:10.29050/harranziraat.718813
ÖZ

Bu çalışma, Çanakkale ilinde Extreme July ve Glohaven şeftali çeşitlerinde Tropinota (Epicometis) hirta (Poda) (Coleoptera: Cetoniidae) erginlerini yakalamada en uygun yükseklik ve tuzak renginin belirlenmesi amacıyla yürütülmüştür. Bu amaçla, Hexadecimal kodlu mavi renklerle (\#B4C8E1, \#C4D5E3, \#A6CDE3, \#4D9AC9 ve \#05467A) boyanan leğen tuzaklara ( $35 \times 25 \times 15 \mathrm{~cm}$ ), yakalanan erginlerin çıkışını önlemek için $1 / 3$ oranında su ile doldurulmuş, cezbediciler (Trans-Anethol+Cinnamyl Alcohol, 1:1) leğenlerin üzerinde geçirilen iplere bağlanmış ve aralarında 10 metre mesafe olacak şekilde aynı sıradaki iki ağacın arasına yerde $(0 \mathrm{~cm}), 50$ ve $100 \mathrm{~cm}$ yüksekliğe yerleştirilmiştir. Deneme, 01.03.2019 tarihinde tesadüf blokları deneme desenine göre 2 tekrarlı olarak kurulmuş ve tuzaklara yakalanan erginler 2 gün ara ile 5 Mayıs tarihine kadar sayılmıştır. Her iki şeftali çeşidinde farklı renk ve yükseklikteki tuzaklara örnekleme tarihlerinde yakalanan ergin sayıları istatistiksel olarak karşılaştırılmıştır $(P<0.05)$. Örnekleme süresince Extreme July ve Glohaven çeşidinde tuzaklarda sırasıyla 1461 ve 802 adet T. hirta ergini sayılmıştır. İlk erginler çiçeklenmeden önce 02.03.2019 tarihinde tuzaklara yakalanmış ve çiçeklenmenin \%100'e ulaştığı 18 ve 20 Mart tarihlerinde ergin sayısı Extreme July ve Glohaven çeşidinde en yüksek düzeye ulaşılmıştır. İncelenen \#B4C8E1, \#C4D5E3, \#A6CDE3, \#4D9AC9 ve \#05467A kodlu mavi renk tuzaklara üç yükseklikte de Extreme July çeşidinde 298, 259, 286, 382 ve 236 adet ve Glohaven çeşidinde ise 169, 105, 149, 247 ve 133 adet ergin yakalanmıştır. Ayrıca, 5 farklı tuzakta yerde $(0 \mathrm{~cm}), 50$ ve $100 \mathrm{~cm}$ de Extreme July çeşidinde sırasıyla 450, 634 ve 377 adet; Glohaven çeşidinde ise 213, 344 ve 245 adet ergin kaydedilmiştir. Her iki şeftali çeşidinde üç yükseklikte tuzaklara günlük yakalanan ortalama T. hirta ergin sayıları arasındaki fark istatistiksel olarak önemli bulunmuştur $(P<0.05)$. En fazla T. hirta ergini \#4D9AC9 kodlu tuzakla; Extreme July ve Glohaven çeşidinde sırasıyla yerde $(0 \mathrm{~cm})$ ve $50 \mathrm{~cm}$ yükseklikte yakalanmıştır.

Anahtar Kelimeler: Şeftali, Extreme July, Glohaven, Tropinota hirta, Mavi leğen tuzaklar

\section{ABSTRACT}

This study was carried out to determine the most suitable height and trap colour for catching Tropinota (Epicometis) hirta (Poda) (Coleoptera: Cetoniidae) adults in Extreme July and Glohaven peach varieties in Çanakkale province. For this purpose, the basin traps (35 $225 \times 15 \mathrm{~cm}$ ), painted with hexadecimal coded colours (\# B4C8E1, \# C4D5E3, \# A6CDE3, \# 4D9AC9 and \# 05467A) 1/3 water was filled into basins to prevent adults of $T$. hirta, the lures (Trans-Anethol + Cinnamyl Alcohol, 1: 1) attached to the fixing ropes that were passed over the basins and with a distance of 10 meters between the two trees in the same rows were placed on the ground $(0 \mathrm{~cm}), 50$ and $100 \mathrm{~cm}$ high. The experiment was established on 01.03.2019 with 2 repetitions according to the random blocks trial pattern and adults caught into traps per two days were counted until May 5th. In both peach varieties, the number of adult traps caught at the sampling dates were compared based on the same
(C) Copyright 2018 by Harran University Faculty of Agriculture. Available on-line at www.dergipark.gov.tr/harranziraat

This work is licensed under $\begin{array}{lr}\text { Creative } & \text { Commons } \\ \text { Attribution-Non } & \text { Commercial }\end{array}$ Attribution-Non Comm
4.0 International License. 
and different heights $(\mathrm{P}<0.05)$. During the sampling period, in the traps of Extreme July and Glohaven peach cultivars were caught 1461 and 802 individuals of $T$. hirta adults in traps, respectively. First adults were captured in the traps before the blooming period of peach trees on 02.03 .2019 and on March 18 and 20, when flowering reached $100 \%$, the number of adults trapped reached the highest level in Extreme July and Glohaven variety, respectively. The examined \#B4C8E1, \#C4D5E3, \#A6CDE3, \#4D9AC9 ve \#05467A coded blue colour traps at three heights in during flowering period of Extreme July and Glohaven varieties were caught 298, 259, 286, 382, 236 and 169, 105, 149, 247, 133 adults of $T$. hirta respectively. Also, in Extreme July and Glohaven cultivars 449, 630, 377 and 213, 346, 241 adults were recorded in the traps at the heights of 0 $\mathrm{cm}, 50 \mathrm{~cm}$ and $110 \mathrm{~cm}$, respectively. The difference between the average number of $T$. hirta adults caught daily in traps at three heights in both peach varieties was found statistically significant $(P<0.05)$. Most $T$. hirta adults were caught with the trap \# 4D9AC9 on the ground $(0 \mathrm{~cm})$ and $50 \mathrm{~cm}$ high, in Extreme July and Glohaven peach cultivars, respectively.

Key Words: Peach, Extreme July, Glohaven, Tropinota hirta, Blue basin traps

\section{Giriş}

Avrupa, Ortadoğu ve Kuzey Afrika ülkelerinde varlığı bilinen Tropinota (Epicometis) hirta (Poda,1760) (Coleoptera; Cetoniidae) erginleri toplam 48 kültür bitkisinde kaydedilmiştir (Subchev et al., 2011). Türkiye'de farklı bölgelerde varlığı bildirilen $T$. hirta erginleri Çanakkale ilinde başta şeftali olmak üzere kiraz, erik, kayısı ve elma alanlarında tespit edilmiştir (Gezer ve Özpınar, 2015). Meyve ağaçlarının çiçek ve polenlerinde zararlı olan T. hirta erginlerinin (Özbek, 2008) süs bitkileri, kanola ve aspir gibi diğer kültür bitkilerinde de zararlı olması (Vuts et al., 2010a; Esfahani et al., 2012; Ursache et al., 2017) ergin varlığının uzun bir döneme yayılmasına olanak sunmaktadır. Son yıllarda meyve alanlarında bu zararlıya karşı gerekli önlemler alınmadığı taktirde önemli ürün kayıplarına neden olduğu, armut ağaçlarının çiçeklerinde \%90-100 oranında (Kara, 1992) ve kiraz ağaçlarında ise \%70'e varan oranlarda zarar yaptığı tespit edilmiştir (Kutinkova and Andreev, 2004; Razov et al., 2009).

Erken ilkbaharda meyve ağaçlarının çiçeklenme döneminde bal arıları ve diğer tozlayıcı böcek türlerinin bahçelerde yoğunlaşması nedeniyle, bu türlere vereceği zarardan dolayı T. hirta erginlerine karşı kimyasal mücadele önerilmemektedir. Bunun yerine cezbedicilerle renk tuzakların kullanımına öncelik verilmektedir (Vuts et al., 2010 b). Farklı meyve türlerinde çiçeklenme öncesi ve sonrası dönemlerde $T$. hirta erginlerini yakalamada kullanılan renk tuzakların etkinliğinin değiştiği tespit edilmiştir (Aydın, 2011). Yapılan çalışmalarda $T$. hirta erginlerini yakalamada mavi rengin en iyi sonucu verdiği ve ülkemizde farklı bölgelerde mavi renk huni tuzaklar ile mavi renk leğen tuzakların başarılı olduğu belirlenmiştir (Sağdaş, 2011; Arslan ve Aslan, 2015; Gezer ve Özpınar, 2015).

Macaristan'da yapılan bir çalışmada ise $T$. hirta erginlerini yakalamada cezbedici "cinnamyl alkol ve trans-anetholün 1:1" karışımının iyi sonuç verdiği (Toth et al., 2003), açık mavi renk tuzaklara cezbedicinin eklenmesiyle başarının arttığı (Schmera et al., 2004) ve ilave olarak cezbediciye sentetik çiçek bileşikleri eklenerek ergin yakalamadaki etkinliğin yükseldiği bildirilmiştir (Vuts et al., 2010a).

Çanakkale ilinde farklı meyve türlerinin yetiştirilmesiyle ilkbaharda çiçeklenme periyodunun uzaması $T$. hirta erginleri için uygun ortam sağlamaktadır. Özellikle ilkbaharda erken çiçek açan şeftali alanlarında ergin sayısının yüksek seviyelere ulaştığı belirlenmiştir (Gezer ve Özpınar, 2015). Buna karşın meyve seyreltme işlemi nedeniyle yörede şeftalide $T$. hirta ergin zararının önemsenmediği ve bu nedenle gerekli önlemlerin alınmadığı tespit edilmiştir. Böylece şeftaliden sonra çiçek açan kiraz alanlarında $T$. hirta erginlerinin ürün kaybına neden olmasıyla, mücadele bu alanlarda yapılmaktadır. Zira T. hirta ile ilgili çalışmaların çoğu da kiraz alanlarına aittir. Ancak, Çanakkale ilinde bahçelerin yan yana veya çoğunlukla karışık tesis edilmiş olması ve şeftali üretiminin il ekonomisindeki önemi bu alanlarda $T$. hirta ile mücadeleyi zorunlu kılmaktadır. Böylece kiraz alanlarında yapılacak mücadeleye vereceği katkı yanında şeftali alanlarında da yol gösterici olacaktır. Meyve alanlarında T. hirta erginleri ile mücadelede mavi renk tuzakların başarılı olduğu (Vuts et al., 2012), kiraz alanlarında incelenen mavi renklerden açık mavi ve açık çelik mavisi rengin öne çıktığı (Aydın, 2011; Yaşar ve ark., 2013), ticari 
tuzaklarda ise parlament mavisinin kullanıldığı bildirilmiştir (Sağdaş, 2011). Şeftali alanlarında ise bu konuda yeterli çalışma yapılmamıştır. Dolayısıyla bu çalışmada, yörenin meyve ürün deseni de esas alınarak, Çanakkale ilinde yaygın olarak yetiştiriciliği yapılan çiçek yapısı ve çiçek rengi farklı olan ve aralarında bir haftalık hasat süresi bulunan, orta geçci Extreme July ve Glohaven şeftali çeşitlerinde $T$. hirta erginlerini yakalamada en uygun tuzak yüksekliği ve tuzak renginin belirlenmesi amaçlanmıştır.

\section{Materyal ve Metot}

Çalışma, Çanakkale ilinde Extreme July ve Glohaven çeşitleri ile tesis edilmiş üreticiye ait 5'er dekarlık şeftali bahçesinde 2019 yılı mart ve nisan aylarında yürütülmüştür. Çanakkale koşullarında 12 Temmuz'da hasat edilen Extreme July çeşidinde, çiçeklenme 6 Mart 2019'da ve 18 Temmuz'da hasat edilen Glohaven çeşidinde ise 10 Mart tarihinde başlamıştır. Açık pembe çan şeklindeki çiçeklere sahip olan Extreme July çeşidinde tam çiçeklenme 18.03.2019 tarihinde, Glohaven çeşidinde ise 20 Mart'ta gerçekleşmiştir. T. hirta erginlerini yakalamada kullanılan tuzakların renk sayısı, bölgede üreticiler tarafından kullanılan koyu mavi renge (\#05467A) ilave olarak bahçe büyüklükleri de esas alınarak farklı meyve alanlarında yapılan çalışmalarda etkili bulunan mavi renk tonları esas alınarak belirlenmiştir (Toth et al., 2003; Schmera et al., 2004; Aydın, 2011; Sağdaş, 2011; Yaşar ve ark., 2013). Çizelge 1 'de Hexadecimal renk kodları verilen 5 mavi renk boya ile boyanan $35 \times 25 \times 15 \mathrm{~cm}$ ebatlarındaki leğenler bu çalışmada tuzak olarak kullanılmıştır (Şekil 1). Boyanan leğenler Colorimetre cihazla ölçülmüş ve ölçüm değerleri Çizelge 1'de verilmiştir. Yağmurla havalarda fazla suyun drene olması için leğenlerde $2 / 3$ derinlikte 3 adet su taşma deliği açılmıştır.

Çizelge 1. Leğen tuzakların Hexadecimal renk kodları Table 1. Hexadecimal colour codes of the basin traps

\begin{tabular}{|l|c|c|c|c|c|}
\hline Hexadecimal kodları; Hexadecimal codes & \#B4C8E1 & \#C4D5E3 & \#A6CDE3 & \#4D9AC9 & \#05467A \\
\hline HUE değeri; HUE value & 278.46 & 269.32 & 269.32 & 272.39 & 284.98 \\
\hline Kroma değeri; Chroma value & 17.41 & 11.99 & 18.04 & 34.15 & 33.97 \\
\hline
\end{tabular}

HUE: Renk açısı (Ton açısı), Kroma: (Renk doygunluğu); HUE: Color angle (Tone angle), Chroma: (Color saturation)

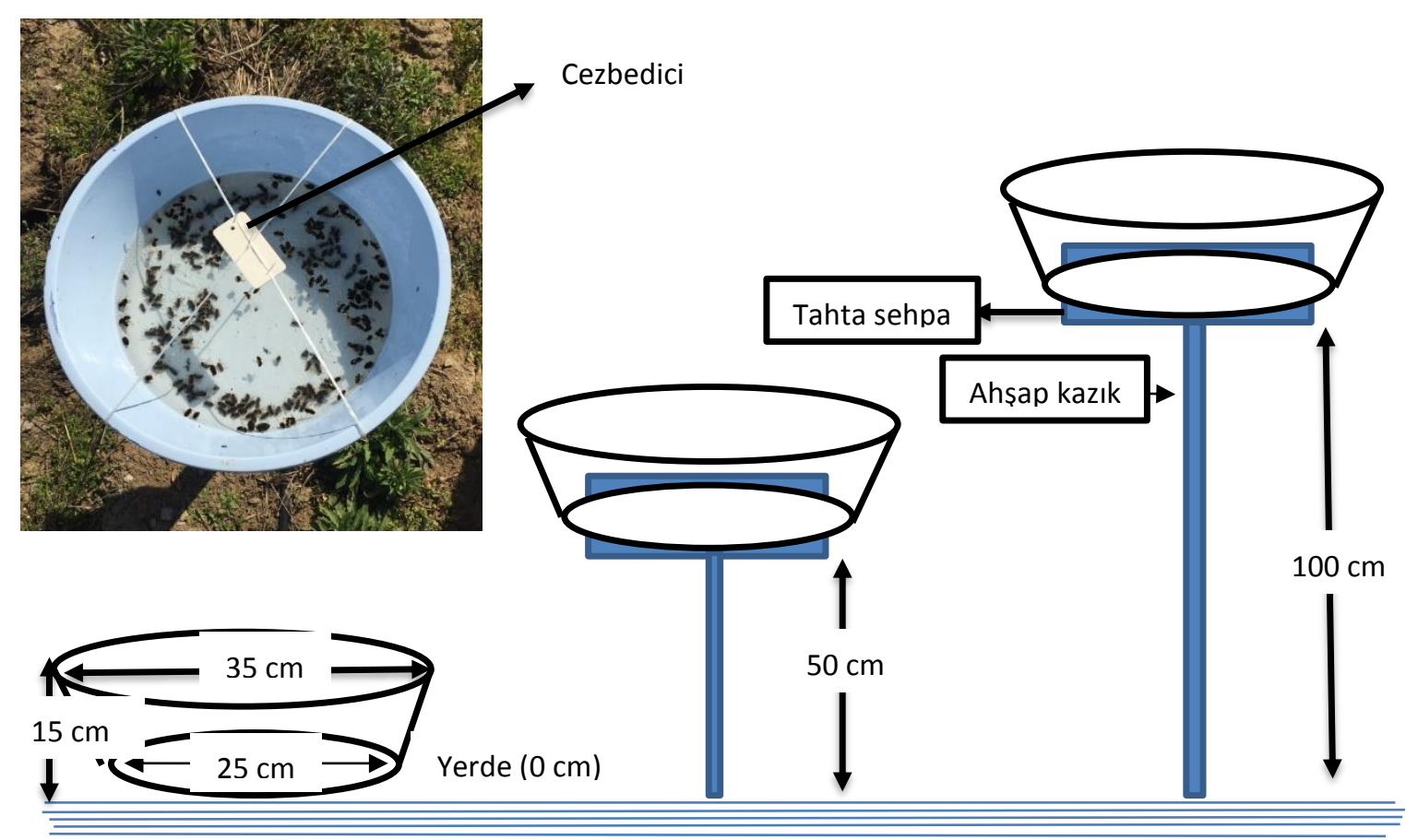

Şekil 1. Tropinota hirta erginlerini yakalamada kullanılan leğen tuzaklar ve yükseklikleri Figure 1. Basin traps and heights used to catch of Tropinota hirta adults 
Extreme July ve Glohaven çeşitleriyle tesis edilmiş şeftali bahçesinde kenar sıralar hariç tutularak 2 sıra boş bırakılmış ve 5 mavi renk tuzak aralarında 10 metre mesafe olacak şekilde 2 ağacın arasına; toprak yüzeyinde $(0 \mathrm{~cm})$ ve topraktan 50 ile $100 \mathrm{~cm}$ yükseklikte bir kazık üzerine monte edilmiş ahşap sehpalara yerleştirilmiştir (Şekil 1). Deneme 2 tekrarlı olarak planlanmış ve aynı renk ve yükseklikteki tuzakların yan yana gelmemesine özen gösterilmiştir. Sehpalardaki leğenlerin etrafına 4'er adet $15 \mathrm{~cm}^{\prime}$ lik çiviler ve yerdeki leğenlere ise demir çubuklar çakılmış ve leğenlerin üstünden geçirilen ipler çivilere ve demir çubuklara bağlanarak tuzakların rüzgârdan uçmaması için sabitlenmiştir. T. hirta'nın ruhsatlı cezbedicisi (100 mg Trans-Anethol+100 mg Cinnamyl Alcohol) leğendeki suya değmeyecek şekilde sabitleme iplerine bağlanmıştır (Şekil 1). Erginlerin tuzaklara yakalanması için, leğenler $1 / 3$ oranında su ile doldurulmuştur. Sayımlar 02.03.2019 tarihinde başlamış ve tuzaklara yakalanan erginler sudan bir süzgeç yardımıyla alınarak kaydedilmiştir. Sayımlar mart ve nisan aylarında 2 gün arayla mayıs ayı başına kadar devam etmiştir. Örnekleme sırasında leğenlerden eksilen su tamamlanmış ve tuzakların etrafındaki yabancı otlar temizlenmiştir. Extreme July ve Glohaven çeşitlerinde yerde $(0 \mathrm{~cm}), 50$ ve $100 \mathrm{~cm}$ yükseklikte 5 farklı mavi tuzağa yakalanan ergin sayısı hazır istatistiksel paket programı (SPSS 23 versiyon) kullanılarak Non-parametrik Kruskal Wallis testiyle $(P<0.05)$ karşılaştırılmıştır.

\section{Araştırma Bulguları ve Tartışma}

Henüz çiçeklenmenin başlamadığı 02.03.2019 tarihinde her iki şeftali çeşidinde, düşük sayıda da olsa bir kısım tuzaklara $T$. hirta erginleri yakalanmıştır (Çizelge 2). Extreme July çeşidinde 6 Mart tarihinden Glohaven çeşidinde ise 10 Mart itibaren ağaçlarda artan çiçeklenme ile yakalanan ergin sayısı artmıştır. Havanın kapalı ve yağışlı olduğu 12-13 Mart tarihlerinde ergin faaliyetinin düşük olması nedeniyle 14 Mart'ta tuzaklara ergin yakalanmamıştır. Ancak takip eden günlerde sıcaklık atışıyla birlikte bahçelerde ergin faaliyeti artmış ve tuzaklara yakalanan ergin sayısı yükselmiştir. Extreme July çeşidinde çiçeklenmenin \%100'e ulaştığı 18 Mart tarihinde ergin sayısı 334 adet ile en yüksek seviyeye ulaşmıştır. Glohaven çeşidinde ise çiçeklenmenin tamamlandığı 20 Mart tarihinde toplam erginlerin \%25.81 (207 adet)'i sayılmıştır. Çiçeklenmenin sona erdiği mart ayı sonunda itibaren tuzaklara yakalanan ergin sayısı azalmıştır. İlkbaharda meyve ağaçları yanında diğer bitkilerin çiçekleri ile de beslenen E. hirta erginleri Afyon ilindeki kiraz ve elma bahçelerinde 31 Mart tarihinde (Sağdaş, 2011), Isparta'da kiraz bahçelerinde ise 23 Mart'ta tuzaklara yakalanmıştır (Yaşar ve ark., 2013). Kahramanmaraş'ta ise badem bahçesinde de ergin uçuşu 1 Mart'a başlamıştır (Arslan ve Aslan 2015). Orta Avrupa'da ise ergin uçuşunun nisan ayında başladığı bildirilmiştir (Vuts et al., 2010b). Görüldüğü üzere $T$. hirta ergin uçuş zamanı bölgelere ve incelenen meyve alanlarına göre değişiklik göstermiştir.

Çizelge 2'de görüldüğü üzere tüm örnekleme süresince Glohaven çeşidinde 802 ve Extreme July şeftali çeşidinde ise 1461 adet ergin tuzaklara yakalanmıştır. Extreme July ve Glohaven çeşitlerindeki toplam erginlerin $\% 75^{\prime} i$ ve $\% 78$ 'i mart ayına ait olduğu tespit edilmiştir. Aralarında bir hafta hasat zaman farkı olan orta geçci Glohaven ve Extreme July çeşitlerinde tuzaklara yakalanan $T$. hirta ergin sayısı oldukça farklı bulunmuştur. Diğer taraftan örnekleme süresince her üç yükseklikte de \#B4C8E1, \#C4D5E3, \#A6CDE3, \#4D9AC9 ve \#05467A Hexadecimal kodlu tuzaklara Extreme July çeşidinde yakalanan toplam ergin sayısı sırasıyla 297, 258, 284, 381 ve 236 adet; Glohaven çeşidinde ise 158, 105, 149, 247 ve 131 adet olarak kaydedilmiştir. Yükseklik esas alınmaksızın kullanılan tuzak renklerinin çeşitlere göre etkinlikleri karşılaştırıldığında; her iki çeşitte en fazla ergin \#4D9AC9 kodlu tuzakta yakalanmıştır. Bu tuzağı sırasıyla \#B4C8E1 ve \#A6CDE3 kodlu renk tuzaklar izlemiştir. En düşük etki ise Glohaven çeşidinde \#C4D5E3 kodlu tuzakta ve Extreme July çeşidinde ise koyu mavi (\#05467A) renk tuzakta tespit edilmiştir. 
Çizelge 2.Extreme July ve Glohaven şeftali çeşidinde üç yükseklikte 5 mavi renk leğen tuzağa farklı tarihlerde yakalanan Tropinota hirta ergin sayıları

Table 2. The number of Tropinota hirta adult captured to 5 blue basins traps on the different dates in three hights in Glohaven and Extreme July peach variety.

\begin{tabular}{|c|c|c|c|c|c|c|c|c|c|c|c|c|c|c|c|c|c|c|c|c|c|c|c|c|c|c|c|c|c|c|c|}
\hline \multicolumn{3}{|c|}{ Çeşitler; Varieties } & \multicolumn{14}{|c|}{ Glohaven } & \multicolumn{15}{|c|}{ Extreme July } \\
\hline \multirow{2}{*}{\begin{tabular}{|l} 
Kodlar; Codes \\
Yük.; Height \\
\end{tabular}} & \multicolumn{3}{|c|}{ \#B4C8E1 } & \multicolumn{3}{|c|}{ \#C4D5E3 } & \multicolumn{3}{|c|}{ \#A6CDE3 } & \multicolumn{3}{|c|}{ \#4D9AC9 } & \multicolumn{3}{|c|}{ \#05467A } & \multirow[b]{2}{*}{ Top } & \multicolumn{3}{|c|}{ \#B4C8E1 } & \multicolumn{2}{|c|}{ \#C4D5E3 } & \multicolumn{3}{|c|}{ \#A6CDE3 } & \multicolumn{3}{|c|}{ \#4D9AC9 } & \multicolumn{3}{|c|}{$\# 05467 A$} & \\
\hline & 0 & 50 & 100 & 0 & 50 & 100 & 0 & \begin{tabular}{|l|l|}
50 & 1 \\
\end{tabular} & 100 & \begin{tabular}{|l|l}
0 & 5 \\
\end{tabular} & \begin{tabular}{|l|l}
50 & 1 \\
\end{tabular} & 100 & 0 & 50 & 100 & & \begin{tabular}{|l|l|}
0 & 5 \\
\end{tabular} & \begin{tabular}{l|l}
50 & 10 \\
\end{tabular} & 00 & \begin{tabular}{l|l}
0 & 50 \\
\end{tabular} & 100 & 0 & 50 & 100 & 0 & 50 & 100 & 0 & 50 & 100 & Top \\
\hline 02.03 .2019 & 0 & 1 & 0 & 0 & 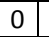 & 8 & 0 & 0 & 0 & 10 & 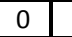 & & & 1 & & 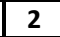 & 0 & & 0 & 0 & 0 & 1 & 1 & & 0 & 1 & 0 & & 0 & 0 & 5 \\
\hline & 0 & 0 & & 0 & & $\mathrm{c}$ & 0 & 10 & & 1 & 1 & & & 0 & & & 0 & & & 1 & & 3 & & & & & & & & & 10 \\
\hline & 0 & 1 & c & 3 & & 0 & 1 & 0 & c & 1 & 0 & & & & & & 6 & & & 1 & & 2 & & & & & & & & & 23 \\
\hline & 11 & 9 & 5 & 3 & & 3 & 5 & 77 & $\mathrm{c}$ & \begin{tabular}{l|l}
9 & 1 \\
\end{tabular} & 14 & & & & & 8 & 5 & & & \begin{tabular}{l|l|}
5 & 11 \\
\end{tabular} & & 5 & 6 & & 28 & 10 & & & 12 & & 13 \\
\hline & 4 & 15 & 4 & 6 & & 6 & 2 & 2 & 4 & \begin{tabular}{|l|l}
5 & 1 \\
\end{tabular} & 15 & & & & & 72 & \begin{tabular}{|l|l|}
11 & 2 \\
\end{tabular} & 23 & & \begin{tabular}{l|l|}
6 & 23 \\
\end{tabular} & & 7 & 21 & 13 & 0 & 15 & & 13 & 1 & & 90 \\
\hline & 6 & 1 & 1 & 1 & 3 & 2 & 1 & 12 & 3 & \begin{tabular}{|l|l}
3 & 1 \\
\end{tabular} & 10 & & & 3 & & 40 & 5 & & & 3 & & 4 & 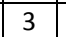 & & & & & & & & 54 \\
\hline & 0 & 0 & c & 0 & 5 & $\mathrm{c}$ & 10 & 10 & $\mathrm{c}$ & 10 & 0 & & & $\mathrm{c}$ & & & 0 & & & 0 & & 0 & & & & & & & & & 0 \\
\hline & 4 & 5 & 5 & 2 & 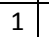 & 4 & 4 & 6 & 1 & \begin{tabular}{l|l}
4 & 1 \\
\end{tabular} & 14 & & & 2 & & 57 & \begin{tabular}{|l|l}
5 & 1 \\
\end{tabular} & 11 & & 2 & & 5 & 12 & & 1 & 11 & & & & & 97 \\
\hline & 3 & 2 & 2 & 0 & 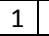 & 5 & 1 & 4 & 3 & 3 & 7 & & & 5 & 1 & 50 & \begin{tabular}{l|l}
21 & 2 \\
\end{tabular} & \begin{tabular}{l|l}
25 & 2 \\
\end{tabular} & 21 & \begin{tabular}{l|l|}
8 & 24 \\
\end{tabular} & 20 & 3 & 28 & 0 & 45 & 33 & 20 & 16 & 10 & 10 & 334 \\
\hline & 12 & 10 & 1 & 5 & \begin{tabular}{|l|l|l|}
14 & \\
\end{tabular} & 16 & 3 & 20 & 12 & \begin{tabular}{l|l}
15 & 3 \\
\end{tabular} & 39 & & & 16 & 10 & 207 & \begin{tabular}{|l|l}
5 & 1 \\
\end{tabular} & 13 & & \begin{tabular}{l|l|}
1 & 10 \\
\end{tabular} & & 2 & 14 & 4 & & & & & 13 & & 11 \\
\hline & 1 & 13 & ( & 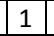 & 2 & 1 & 0 & 0 & 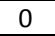 & 1 & T. & & & 1 & & 14 & 1 & & & 0 & & 0 & & & & & & & & & 29 \\
\hline & 1 & 1 & 1 & 0 & 1 & 2 & 2 & 1 & 1 & 5 & 5 & & & & & 0 & 3 & & & 2 & & 2 & & & & & & & & & 33 \\
\hline & 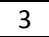 & 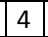 & 5 & 2 & 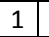 & 5 & 2 & 1 & 7 & \begin{tabular}{l|l}
2 & 1 \\
\end{tabular} & 1 & & & 13 & & 54 & 6 & & & 6 & 15 & 2 & 10 & & 11 & & & & & & 38 \\
\hline & 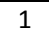 & 1 & c & 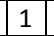 & 0 & 0 & 0 & 10 & c & 1 & 3 & & & 0 & & & 0 & & & 1 & & 2 & & & & & & & & & 16 \\
\hline & 0 & 0 & ( & 0 & & 0 & 0 & c & 0 & 1 & 0 & & & c & & & & & & 0 & & 0 & & & & & & & U & & 1 \\
\hline & 4 & 14 & 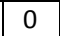 & 0 & 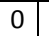 & 1 & 2 & 1 & 1 & 2 & 1 & & & C & & 17 & 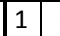 & & & 0 & & 3 & & & & & & & 2 & & 27 \\
\hline & 2 & 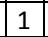 & c & 0 & ( & 0 & 3 & 0 & 0 & 0 & 0 & & & $\mathrm{c}$ & & & & & & 5 & & 3 & & & \pm & & & & 2 & & 31 \\
\hline & 1 & 1 & 3 & 0 & 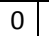 & 0 & 1 & 1 & 7 & 1 & 2 & & ( & 1 & & 2 & 2 & & & 0 & & 3 & & & 4 & & & & 6 & & 55 \\
\hline & 0 & 0 & c & 0 & 0 & 1 & 0 & c & 3 & 0 & 0 & & 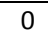 & 0 & & & 1 & & & 1 & & 0 & 2 & & & & & & 2 & & 33 \\
\hline & 0 & 0 & 3 & 0 & t. & 0 & 0 & 1 & 6 & 1 & 3 & 3 & 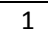 & 7 & & 3 & 2 & - & & 0 & & 1 & 4 & & 8 & & & & 2 & & 8 \\
\hline & 0 & 0 & 0 & 0 & 0 & 0 & 0 & 1 & 0 & 0 & 0 & 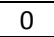 & C & 0 & & & 2 & 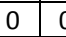 & & 0 & & \begin{tabular}{l|}
1 \\
\end{tabular} & 0 & & 5 & & 0 & & 0 & & 1 \\
\hline & 1 & 11 & 0 & 0 & 2 & 1 & 0 & 2 & 2 & 2 & 0 & 3 & ( & 2 & & & 3 & & & 4 & & 0 & 4 & & 5 & 4 & 4 & & 4 & & 52 \\
\hline & 0 & 1 & 1 & 0 & 0 & 0 & 1 & 4 & 5 & 0 & 0 & 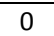 & 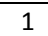 & 0 & & 14 & 0 & & & 0 & & 1 & & & & 3 & & & 1 & & 16 \\
\hline & 0 & 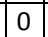 & 0 & 0 & 1. & 0 & 0 & 0 & 0 & 1 & 0 & 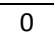 & ( & 0 & & & 1 & & & 0 & & 0 & & & & & & & U & & 9 \\
\hline & 0 & 13 & 1 & 0 & 0 & 0 & 1 & 0 & 2 & 0 & $I$ & $c$ & 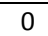 & 1 & & & 2 & & & 0 & & 2 & 0 & & 1 & & U & & 0 & & 8 \\
\hline & 2 & 0 & 0 & 1 & 0 & 0 & 1 & 1 & 0 & 3 & 2 & 0 & 0 & 1 & & & 1 & & & 0 & & 0 & 1 & & 1 & 0 & 0 & & 0 & 0 & 6 \\
\hline & 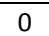 & 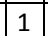 & 2 & 0 & 0 & 0 & 0 & 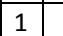 & 2 & 2 & 2 & 0 & 0 & 1 & & 1 & 0 & & & 0 & & 0 & 1 & & 2 & 2 & 3 & & 0 & & 15 \\
\hline D19 & 1 & 0 & 1 & 1 & 0 & 0 & 0 & 1 & 1 & 1 & 2 & 1 & 0 & 0 & & 10 & 0 & . & & 1 & 1 & 1 & 3 & & 1 & 1 & 2 & 0 & 0 & 0 & 17 \\
\hline & 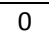 & 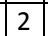 & 0 & 0 & 0 & 0 & 0 & 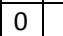 & 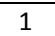 & 1 & 1 & 0 & 0 & 1 & & & 1 & & & 0 & & 0 & 2 & & 0 & 0 & 0 & 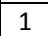 & 0 & 0 & 4 \\
\hline & 0 & 0 & 0 & 1 & 1 & 0 & 0 & 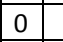 & 2 & 3 & 0 & 0 & 1 & 0 & & & 1 & 0 & & 1 & & 1 & 0 & & 0 & 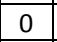 & 0 & 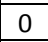 & 0 & 0 & 7 \\
\hline 03. & 0 & 10 & 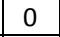 & 0 & 0 & 0 & 1 & 0 & 0 & 0 & 0 & 0 & 0 & 1 & 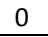 & & 1 & 0 & 2 & 0 & 0 & 0 & 0 & 2 & 2 & 0 & 0 & 0 & 0 & 0 & 8 \\
\hline opla & 57 & 68 & 44 & 27 & 31 & 47 & 30 & \begin{tabular}{|l|l}
56 &
\end{tabular} & 63 & \begin{tabular}{|l|l}
68 & 1 \\
\end{tabular} & 135 & 44 & 31 & 54 & 47 & 802 & $\begin{array}{ll}90 & 1\end{array}$ & \begin{tabular}{l|l}
129 & 7 \\
\end{tabular} & 79 & \begin{tabular}{l|l}
49 & 124
\end{tabular} & $\begin{array}{lll}4 & 86 \\
\end{array}$ & 53 & 129 & 103 & 178 & 128 & 76 & 79 & 124 & 33 & 1461 \\
\hline tal & & 169 & & & 105 & & & 149 & & & 247 & & & 133 & & 2 & & 298 & & 25 & & & 286 & & & 382 & & & 236 & & 146 \\
\hline
\end{tabular}

Toprak yüzeyinde $(0 \mathrm{~cm}), 50$ ve $100 \mathrm{~cm}$ yükseklikteki tuzaklara Extreme July çeşidinde sırasıyla toplam 450, 634 ve 377 adet ve Glohaven çeşidinde ise 213, 344 ve 245 adet ergin yakalanmıştır. Her iki çeşitte de en fazla ergin 50 $\mathrm{cm}$ yükseklikteki tuzaklarda sayılmıştır. Bu sayıyı, Extreme July çeşidinde toprak yüzeyindeki $(0 \mathrm{~cm})$ ve Glohaven çeşidinde ise $100 \mathrm{~cm}$ yükseklikteki tuzaklar izlemiştir.

Farklı yüksekliklerde tuzaklara yakalanan toplam ergin sayıları karşılaştırıldı̆̆ında; \#B4C8E1 kodlu tuzak her iki şeftali çeşidinde $50 \mathrm{~cm}$ de, \#C4D5E3 ve \#A6CDE3 kodlu tuzak ise Glohaven çeşidinde 100 $\mathrm{cm}^{\prime}$ de ve Extreme July çeşidinde ise $50 \mathrm{~cm}$ yükseklikte daha fazla ergin yakalamıştır. En fazla $T$. hirta erginin yakalandığı \#4D9AC9 renk tuzak ise Glohaven çeşidinde $50 \mathrm{~cm}$ 'de ve Extreme July çeşidinde ise yerde $(0 \mathrm{~cm})$ en iyi sonucu vermiştir. \#05467A kodlu tuzakta ise her iki çeşit de $50 \mathrm{~cm}$ de daha fazla ergin yakalanmıştır. Extreme July ve
Glohaven çeşitlerinde üç yükseklikte ve farklı renk tuzaklarda örnekleme tarihlerine göre yakalanan ortalama ergin sayıları arasındaki fark istatistiksel olarak karşılaştırılmıştır (Çizelge 3 ve 4).

Çizelge 3. incelendiğinde, Extreme July çeşidinde toprak yüzeyindeki $(0 \mathrm{~cm}) 5$ tuzağa yakalanan ortalama ergin sayısı arasındaki fark istatistiksel olarak önemli bulunmuştur $(P<0.05)$. \#4D9AC9 kodlu tuzak; \#B4C8E1 ve \#05467A kodlu tuzaklarla aynı grupta yer almasına karşın, yakalanan 6.13 adet erginle en yüksek sayıya ulaşmıştır. Yerden $50 \mathrm{~cm}$ yükseklikteki tuzaklara yakalanan ortalama ergin sayısı arasındaki fark önemsiz çıkmıştır. Ancak, tüm tuzaklarda diğer iki yüksekliğe göre daha fazla ergin yakalanmıştır. Yerden $100 \mathrm{~cm}$ yükseklikteki tuzaklarda ise yakalanan ergin sayısı arasındaki fark önemli olup, en düşük ergin sayısı koyu mavi (\#05467A) tuzakta ve en yüksek ergin sayısı ise \#A6CDE3 kodlu tuzakta elde edilmiştir. 
Çizelge 3. Extreme July çeşidinde tuzaklara yakalanan Tropinota hirta ergin sayılarının karşılaştırılması (Ort. \pm S.H.) Table 3. Comparison of numbers of Tropinota hirta adult caught in traps in Extreme July peach variety (Avg. \pm S.H.)

\begin{tabular}{|l|l|l|l|l|l|c|c|}
\hline & \#B4C8E1 & \#C4D5E3 & \#A6CDE3 & \#4D9AC9 & \#05467A & H değeri; H value & P değeri; P value \\
\hline $\begin{array}{l}\text { Toprak yüzeyi } \\
\text { Soil surface }\end{array}$ & $\begin{array}{l}3.10 \pm 0.78 \\
\text { ab A }\end{array}$ & $\begin{array}{l}1.68 \pm 0.42 \\
\text { b B }\end{array}$ & $\begin{array}{l}1.82 \pm 0.33 \\
\text { b B }\end{array}$ & $\begin{array}{l}6.13 \pm 1.80 \\
\text { a A }\end{array}$ & $\begin{array}{l}2.72 \pm 0.70 \\
\text { ab AB }\end{array}$ & 14.907 & $0.005^{*}$ \\
\hline $50 \mathrm{~cm}$ & $\begin{array}{l}4.41 \pm 1.19 \\
\text { a A }\end{array}$ & $\begin{array}{l}4.24 \pm 0.77 \\
\text { a A }\end{array}$ & $\begin{array}{l}4.41 \pm 0.74 \\
\text { a A }\end{array}$ & $\begin{array}{l}4.37 \pm 1.25 \\
\text { a AB }\end{array}$ & $\begin{array}{l}4.27 \pm 0.79 \\
\text { a A }\end{array}$ & 0.768 & 0.943 \\
\hline $100 \mathrm{~cm}$ & $\begin{array}{l}2.72 \pm 0.83 \\
\text { ab A }\end{array}$ & $\begin{array}{l}2.97 \pm 0.90 \\
\text { ab AB }\end{array}$ & $\begin{array}{l}3,55 \pm 0,88 \\
\text { a AB }\end{array}$ & $\begin{array}{l}2.62 \pm 0.74 \\
\text { ab B }\end{array}$ & $\begin{array}{l}1.13 \pm 0.41 \\
\text { b B }\end{array}$ & 10.031 & $0.040^{*}$ \\
\hline H değeri; H value & 2.267 & 9.493 & 9.003 & 7.053 & 12.472 & & \\
\hline P değeri; P value & 0.322 & $0.009 *$ & $0.011^{*}$ & $0.029 *$ & $0.002 *$ & & \\
\hline
\end{tabular}

Aynı satırda aynı küçük harfle $(P<0,05 ; n=29 ; d f=4)$ ve aynı sütunda aynı büyük harfle $(P<0,05 ; n=29 ; d f=4)$ gösterilen ortalamalar arasındaki fark istatistiksel olarak önemli değildir. Means within a row with the same lower case letter $(P<0,05 ; n=29 ; d f=4)$ and a column with the same upper-case letter $(P<0,05 ; n=29$; $\mathrm{df}=4$ ) are not significantly different.

Tuzakların farklı yükseklikteki etkinlikleri karşılaştırıldı̆̆ında; \#B4C8E1 kodlu tuzağın üç yükseklikte de yakaladığı ergin sayısı arasındaki fark önemsiz çıkmıştır. \#C4D5E3 kodlu tuzakta ise yakalanan ortalama ergin sayısı arasındaki fark önemli olup, $(P<0.05)$ toprak yüzeyindeki tuzakta yakalanan ergin sayısı diğer iki yüksekliğin gerisinde kalmıştır. En iyi sonuç 4.24 adet ergin ile yerden $50 \mathrm{~cm}$ yükseklikteki tuzakta sağlanmıştır. \#A6CDE3 kodlu tuzakta üç yükseklikte yakalanan ortalama ergin sayısı arasındaki fark önemli bulunmuş ve en iyi sonuç $50 \mathrm{~cm}$ yükseklikteki tuzakta elde edilmiştir. \#4D9AC9 kodlu tuzağa yakalanan ortalama ergin sayısı arasındaki fark da önemli bulunmuştur. En iyi sonuç 6.13 adet ergin ile yerdeki $(0 \mathrm{~cm})$ tuzakta elde edilmiştir. Bunu 4.37 erginle 50 cm'deki tuzak izlemiştir. \#05467A kodlu tuzağa ise üç yükseklikte yakalanan ergin sayısı arasındaki fark istatistiksel olarak önemli bulunmuştur. Yerde ve $50 \mathrm{~cm}$ yükseklikte yakalanan ergin sayısı aynı grupta yer almasına rağmen, $50 \mathrm{~cm}$ de daha fazla ergin yakalanmıştır. \#B4C8E1, \#C4D5E3, \#A6CDE3 ve \#05467A kodlu tuzaklarda en iyi sonuç $50 \mathrm{~cm}$ 'de \#4D9AC9 kodlu tuzakta ise toprak yüzeyinde elde edilmiştir. Extreme July çeşidinde \#4D9AC9 kodlu tuzak yerde tüm tuzaklardan daha fazla ergin yakalamıştır.

Glohaven şeftali çeşidinde tuzaklara farklı yüksekliklerde yakalanan ortalama ergin sayıları istatistiksel olarak karşılaştırılmış olup, sonuçları Çizelge 4'te verilmiştir.

Çizelge 4. Glohaven çeşidinde tuzaklara yakalanan Tropinota hirta ergin sayılarının karşılaştırılması (Ort. \pm S.H) Table 4. Comparison of numbers of Tropinota hirta adult caught in traps in Glohaven peach variety (Avg. \pm S.H.)

\begin{tabular}{|c|c|c|c|c|c|c|c|}
\hline & \#B4C8E1 & \#C4D5E3 & \#A6CDE3 & \#4D9AC9 & $\# 05467 A$ & H değeri; H Value & $P$ değeri; $P$ value \\
\hline $\begin{array}{l}\text { Toprak yüzeyi; } \\
\text { Soil surface }\end{array}$ & $\begin{array}{l}1.96 \pm 0.57 \\
a b A\end{array}$ & $\begin{array}{l}0.93 \pm 0.28 \\
\text { b A }\end{array}$ & $\begin{array}{l}1.03 \pm 0.25 \\
a b A\end{array}$ & $\begin{array}{l}2.34 \pm 0.58 \\
\text { a } A B\end{array}$ & $\begin{array}{l}1.07 \pm 0.29 \\
a b A\end{array}$ & 9.517 & 0.049* \\
\hline $50 \mathrm{~cm}$ & $\begin{array}{l}2.31 \pm 0.65 \\
a b A\end{array}$ & $\begin{array}{l}1.07 \pm 0.48 \\
\text { b A }\end{array}$ & $\begin{array}{l}1.93 \pm 0.72 \\
\text { b A }\end{array}$ & $\begin{array}{l}4.65 \pm 0.91 \\
\text { a A }\end{array}$ & $\begin{array}{l}1.82 \pm 0.60 \\
\text { b A }\end{array}$ & 18.903 & $0.001 *$ \\
\hline $100 \mathrm{~cm}$ & $\begin{array}{l}1.51 \pm 0.43 \\
\text { a A }\end{array}$ & $\begin{array}{l}1.62 \pm 0.61 \\
\text { a A }\end{array}$ & $\begin{array}{l}2.17 \pm 0.53 \\
\text { a A }\end{array}$ & $\begin{array}{l}1.51 \pm 0.70 \\
\text { a B }\end{array}$ & $\begin{array}{l}1.62 \pm 0.48 \\
\text { a A }\end{array}$ & 3.548 & 0.471 \\
\hline $\mathrm{H}$ değeri; $\mathrm{H}$ value & 1.114 & 0.109 & 1.961 & 14.376 & 0.619 & & \\
\hline$P$ değeri; $P$ value & 0.573 & 0.947 & 0.375 & $0,001^{*}$ & 0.734 & & \\
\hline
\end{tabular}

Aynı satırda aynı küçük harfle $(P<0,05 ; n=29 ; d f=4)$ ve aynı sütunda aynı büyük harfle $(P<0,05 ; n=29 ; d f=4)$ gösterilen ortalamalar arasındaki fark istatistiksel olarak önemli değildir. Means within a row with the same lower case letter $(P<0,05 ; n=29 ; d f=4)$ and a column with the same upper-case letter $(P<0,05 ; n=29$; $\mathrm{df}=4$ ) are not significantly different.

Toprak yüzeyindeki tuzaklara yakalanan ortalama ergin sayıları arasındaki fark istatistiksel olarak önemli bulunmuştur. En iyi sonuç \#4D9AC9 kodlu tuzakta alınmıştır. \#B4C8E1, \#A6CDE3 ve \#05467A kodlu tuzakların etkisi aynı düzeyde gerçekleşmiştir. Yerden $50 \mathrm{~cm}$ yükseklikteki tuzaklarda yakalanan ortalama ergin sayısı arasındaki fark istatistiksel olarak ( $P=0.001)$ önemli bulunmuştur. \#4D9AC9 kodlu tuzak 4.65 adet erginle en iyi sonucu vermiştir. Yerden 100 
cm'deki tuzaklara yakalanan ortalama ergin sayısı arasındaki fark ise istatistiksel olarak önemsiz çıkmıştır.

Glohaven şeftali çeşidinde tuzakların farklı yüksekliklerdeki etkisi karşılaştırıldığında, \#4D9AC9 kodlu tuzak dışında kalan tuzaklara yakalanan ergin sayıları arasındaki fark önemsiz bulunmuştur. Üç yükseklikte \#4D9AC9 kodlu tuzağa yakalanan ortalama ergin sayısı arasındaki fark istatistiksel olarak önemli bulunmuştur $(P=0.001)$. Yerde ve $50 \mathrm{~cm}$ de yakalanan ergin sayısı aynı grupta yer almasına rağmen, $50 \mathrm{~cm}$ yükseklikte (4.65 ergin) en iyi sonuç alınmıştır.

Her iki şeftali çeşidinde mavi rengin 5 farklı tonundaki tuzaklara yakalanan ergin sayısı tuzakların rengine ve konumlanan yüksekliğe göre değişiklik göstermiştir. Benzer sonuçlar kiraz alanlarında yapılan çalışmalarda da tespit edilmiştir. Bazı çalışmalarda koyu mavi renk etkili iken, diğerlerinde açık mavi ve çelik mavisi renk tuzaklara daha fazla ergin yakalanmıştır (Aydın, 2011; Oltean et al., 2015; Vuts et al., 2012; Yaşar ve ark., 2013). Bu çalışmada her iki şeftali çeşidinde en iyi sonucu veren derin gök mavisi (deep sky blue) rengine eşdeğer olarak kabul edilen \#4D9AC9 kodlu tuzakta yakalanan ergin sayısı, Yaşar ve ark., (2013) tarafından kiraz alanlarında huni tuzaklarla yapılan çalışmada 3 . sırda yer almıştır. Dolayısıyla aynı tuzağın farklı meyve alanlarındaki etkinlikleri değişiklik gösterebiliyor. Bu nedenle zararlı ile etkili bir mücadele için tür ve çeşit düzeyinde inceleme yapılarak, mevcut farklılıkların tuzaklarla ortaya konulması gerekmektedir.

Diğer taraftan henüz ağaçlar çiçek açmadan 02.03.2019 tarihinde $T$. hirta erginlerinin bahçelerde mevcut olduğu ve çiçeklenmeye bağlı olarak artan ergin sayısı çiçeklenmenin en üst seviyeye ulaştığı (\%100) dönemde en yüksek düzeye ulaşmıştır. Çiçeklenme sonrası sayıları azalan $T$. hirta erginlerinin varlığı, her iki şeftali bahçesinde yaklaşık bir ay kadar devam etmiştir. $T$. hirta erginlerinin sadece çiçeklerle beslenmediği aynı zamanda tomurcukları da yediği tespit edilmiştir. Yakın mesafede nisan ayı başında çiçek açan kiraz bahçesinin varlığına rağmen, çiçeklenme sonrası erginlerin şeftali bahçelerini tamamen terk ederek yeni çiçek açan alanlara geçmediği görülmüştür. Bu durum, erginlerin ağaçlardaki çiçeklenmeye tamamen bağlı kalmadıklarını göstermiştir. Subchev et al., (2011) Bulgaristan'da T. hirta erginlerinin mart ayının 2. haftasından ağustos ayının sonuna kadar tuzaklara yakalandığını tespit etmiştir. Arslan ve Aslan (2015) ise Kahramanmaraş'ta günlük sıcaklığın $9-10^{\circ} C^{\prime}$ olduğu mart ayının başından itibaren $T$. hirta ergin uçuşunun başladığını ve nisan ayı başında en yüksek seviyeye ulaştığını bildirmiştir. Görüldüğü üzere bölgesel farklıklara rağmen $T$. hirta erginlerinin meyve alanlarındaki varlığının uzun bir dönem devam ettiği ve mücadelenin sadece belli meyve türleri ile sınırlı tutulmaması gerektiği kanısına varılmıştır.

Diğer taraftan yağışlı veya kapalı havalarda tuzaklara yakalanan ergin sayısı azalmış, bu sebepten dolayı 14 Mart ve 30 Mart tarihlerinde tuzaklara erginlerin yakalanmadığı tespit edilmiştir. Buna karşın güneşli ve sıcak havalarda ise yakalanan ergin sayısı artmıştır. Yaşar ve Dahham Dahham (2019) ergin aktivitesinin yağışlı havalarda azaldığı ve güneşli havalarda arttığı şeklinde ifade etmiştir.

Örnekleme süresince 2 ay boyunca Extreme July çeşidindeki tuzaklara 1461 adet ve Glohaven çeşidinde ise 802 adet $T$. hirta ergini yakalanmıştır. Çeşitlere göre ergin sayısındaki bu farkın çiçek rengi ve şekli gibi çeşit özelliğinden ileri geldiği düşünülmüştür. Yaşar ve Dahham Dahham (2019) farklı elma çeşitlerinde erginlerin tercihinde çiçek rengi yanında kokusunun da etkili olabileceğini bildirmiştir. T. hirta erginleri her iki şeftali çeşidinde $\% 42.75$ ve $\% 43.26$ oranla en fazla $50 \mathrm{~cm}$ yükseklikteki tuzaklara yakalanmıştır. Diğer yüksekliklerde yakalanan ergin sayısı çeşitlere göre farklılık göstermiştir. Extreme July çeşidinde toprak yüzeyindeki tuzaklara ve Glohaven çeşidinde ise $100 \mathrm{~cm}$ 'deki tuzaklara daha fazla ergin yakalandığı tespit edilmiştir. Glohaven şeftali çeşidinde ağaçların daha boylu olması ve boy farkı nedeniyle ağaç tacındaki çiçek yoğunluğu ile tuzak yüksekliği arasındaki uyuma bağlanmıştır. Ancak bu 
detayların ayrıca incelenip açığa kavuşturulması gerekmektedir.

\section{Sonuçlar}

Her iki şeftali çeşidinde $T$. hirta erginleri 02.03.2019 tarihinde çiçeklenme öncesi tuzaklara yakalanmış ve çiçeklenmedeki artışla birlikte tuzaklara yakalanan ergin sayısı artmıştır. En yüksek ergin sayısı çiçeklenmenin \%100'e ulaştığı 18-20 Mart tarihinde sayılmıştır. 30 Mart'ta çiçeklenme tamamlandıktan sonra nisan ayı boyunca erginler tuzaklara düşük sayıda da olsa yakalanmaya devam etmiştir. Örneklemenin devam ettiği 5 Mayıs tarihine kadar yaklaşık iki ay boyunca Glohaven çeşidine (802 adet) göre Extreme July çeşidinde (1461 adet) oldukça fazla sayıda $T$. hirta ergini yakalanmıştır. Farklı yüksekliklerde tuzaklara günlük yakalanan ortalama ergin sayıları arasındaki fark istatistiksel olarak anlamlı bulunmuştur. Her iki çeşitte ergin yakalamada \#4D9AC9 kodlu tuzak diğerlerine göre daha iyi sonuç vermiştir. Bu tuzakla en fazla ergin Extreme July çeşidinde yerde $(0 \mathrm{~cm})$ ve Glohaven çeşidinde ise $50 \mathrm{~cm}$ 'de yakalanmıştır. Yörede kullanılan koyu mavi renkli leğen tuzak (\#05467A) diğerlerine göre geride kalmıştır. Bu tuzağın yerine daha başarılı olan \#4D9AC9 kodlu tuzak Extreme July çeşidinde yerde $(0 \mathrm{~cm})$ ve Glohaven çeşidinde ise $50 \mathrm{~cm}$ 'de daha fazla ergin yakaladığı için tercih edilmelidir.

Ayrıca Çanakkale'de yaygın olarak yetiştirilen orta geçci olan bu iki şeftali çeşitte yakalanan $T$. hirta ergin sayısı arasındaki fark oldukça yüksek çıkmıştır. Yörede hasat zamanı aynı olan bu çeşitlerle yapılacak bahçe tesisinde, çeşitlerin diğer özellikleri de göz önüne alınarak Glohaven çeşidine öncelik verilmesi $T$. hirta ergin popülasyonunu baskı altına almada yararlı olacaktır.

\section{Çıkar Çatışması Beyanı: Makale yazarları} aralarında herhangi bir çıkar çatışması olmadığını beyan ederler.

\section{Kaynaklar}

Arslan, Ö. M. ve Aslan, M. M. (2015). Kahramanmaraş ili badem ağaçlarında bakla zınnı (Epicometis hirta (Poda, 1761) (Coleoptera: Scarabaeidae)'nın farklı tuzaklarla yakalanması üzerine araştırma. Kahramanmaraş Sütçü Imam Üniversitesi, Doğa Bilimleri Dergisi, 18 (4), 6-12.

Aydın, G. (2011). Plant phenology-related shifts in color preferences of Epicometis (Tropinota) hirta (Coleoptera: Scarabaeidae: Cetoniinae) adults-key to effective population monitoring and suppression. Florida Entomologist, 94 (4), 832-838.

Esfahani, M. N. , Alizadeh, G., Zarei, Z. ve Esfahani, M. N. (2012). The main insect pests of safflower on various plant parts in Iran. Journal of Agricultural Science and Technology 2 (11), 1281-1288.

Gezer, B. ve Özpınar, A. (2015). Çanakkale ilinde şeftali, elma, kiraz ve kayısılarda Tropinota hirta (Poda) (Coleoptera: Cetoniidae) ergin yoğunluğunu belirlemede farklı tuzakların değerlendirilmesi. Çanakkale Onsekiz Mart Üniversitesi, Ziraat Fakültesi Dergisi, 3(2), 27-34.

Kara, K. (1992). Tropinata hirta (Poda) (Coleoptera: Scarabacidae)'nın Tokat ve çevresindeki konukçuları, yayılışı, zarar düzeyi, bazı biyolojik özellikleri ve mücadele imkanları üzerinde araştırmalar. Cumhuriyet Üniversitesi, Fen Bilimleri Enstitüsü (Yayımlanmamış yüksek lisans tezi), Tokat, $37 \mathrm{~s}$.

Kutinkova, H. ve Andreev, R. (2004). Integrated pest management in sweet cherry (Prunus avium L.) orchards in Bulgaria. Journal of Fruit and Ornamental Plant Research, 12 (1), 41-47.

Oltean I., Macavei, L. I., Vasian, I., Tötös, S., Varga, M. ve Florian, T. (2015). Use of semiochemical products in monitoring and control of Epicometis hirta Poda. Bulletin USAMV Series Agriculture 72 (2) , 453-456.

Özbek, H. (2008) Türkiye'de ılıman iklim meyve türlerini ziyaret eden böcek türleri. Uludağ Arıcılık Dergisi, 8(3), 92-103.

Ražov, J., Barić, B., ve Dutto, M. (2009). Fauna of the cetoniid beetles (Coleoptera: Cetoniidae) and their damages on peach fruits in orchards of Northern Dalmatia, Croatia. Entomol Croat 13(2), 7-20.

Sağdaş, A. (2011). Farklı tuzakların Afyonkarahisar ili Sultandağı ilçesinde kiraz ve elmalarda zarar yapan bakla zınnı (Epicometis (=Tropinata) hirta Poda Coleoptera: Scarabaeidae))'nın yakalanması üzerine etkisi. Süleyman Demirel Üniversitesi, Fen Bilimleri Enstitüsü (Yayımlanmamış yüksek lisans tezi), Isparta, 162s

Schmera, D. Toth, M., Subchev, M., Sredkov, I., Szarukan, I., Jermy, T., ve Szentesi, A., (2004). Importance of visual and chemical cues in the development of an attractant trap for Epicometis (Tropinota) hirta Poda (Coleoptera: Scarabaeidae). Crop Projection, 23 (10), 939-944.

Subchev, M., Toshova, T. B., Andreev, R. A., Petrova, V. D., Maneva, V. D., Spasova, T. S., Marinova, N. T., Minkov, P. M. ve Velchev, D. I. (2011) Employing floral baited traps for detection and seasonal monitoring of 
Tropinota (Epicometis) hirta (Poda) (Coleoptera: Cetoniidae) in Bulgaria. Acta Zoologica Bulgarica, 63(3), 269-276.

Toth, M., Klein, M. G. ve Imrei Z. (2003). Field screening for attractants of scarab (Coleoptera: Scarabaeidae) pests in Hungary. Acta Phytopathologica at Entomologica Hungarica, 38 (3-4), 323-331.

Ursache, P. L., Trotus, E. ve Buburuz, A. A. (2017). Observations concerning the harmful entomofauna from winter rapeseed crops in the conditions of Central of Moldava, between years 2014-2017. Journal of Engineering Studies and Research, 23 (2),33-41.

Vuts, J., Szarukán, I., Subchev M., Toshova T. ve Tóth M. (2010 a). Improving the floral attractant to lure Epicometis hirta Poda (Coleoptera: Scarabaeidae, Cetoniinae). Journal Pest Science, 83 (1), 15-20.

Vuts, J., Baric, B., Razov, J., Toshova, T. B., Subchev, M., Sredkov, I., Tabilio, R., Franco, F. Di, ve Tóth, M. (2010 b). Performance and selectivity of floral attractant- baited traps targeted for cetoniin scarabs (Coleoptera: Scarabaeidae) in Central and Southern Europe. Crop Protection, 29 (10), 1177-1183.

Vuts, J., Kaydan, M. B., Yarimbatman A. ve Tóth, N. (2012). Field catches of Oxythyrea cinctella using visual and olfactory cues. Physiological Entomology, 37 (1), 9296. https://doi.org/10.1111/j.13653032.2011.00820.x

Yaşar, B. ve Dahham Dahham O., A. (2019). Farklı elma çeşitleri üzerine asılan tuzakların Tropinota hirta (Poda, 1761) (Coleoptera: Cetoniidae)'nın yakalaması üzerine etkisi Turkish Journal of Agricultural Research, 6 (1), 57-64.

Yaşar B., Çeşme İ., Baydar M. S., Aysal İ. ve Yazır, A. B. 2013. Farklı mavi renkli huni tuzaklarının kiraz ağaçları çiçeklerinde beslenen bakla zınnı (Epicometis hirta (poda) (coleoptera: scarabaeidae))'nın yakalanması üzerine etkisi. Türkiye Entomoloji Dergisi, 3(2), 99105. 